\title{
A Novel Finite-Control-Set Model Predictive Directive Torque Control Strategy of Permanent Magnet Synchronous Motor with Extended Output
}

\author{
Mingxing Du ${ }^{1, *(\mathbb{D}}$, Ye Tian ${ }^{1}{ }^{(\mathbb{O}}$, Wenbai Wang ${ }^{1, *}$, Ziwei Ouyang ${ }^{1,2}$ and Kexin Wei ${ }^{1}$ \\ 1 Tianjin Key Laboratory of Control Theory \& Applications in Complicated System, Tianjin University of \\ Technology, Tianjin 300384, China; ty_tjut@yeah.net (Y.T.); zo@elektro.dtu.dk (Z.O.); \\ kxwei@tjut.edu.cn (K.W.) \\ 2 Department of Electrical Engineering, Technical University of Denmark, 2800 Kgs. Lyngby, Denmark \\ * Correspondence: dumx@tjut.edu.cn (M.D.); wangwenbai@hotmail.com (W.W.); \\ Tel.: +86-22-6021-4268 (M.D.); +86-22-6021-4268 (W.W.)
}

Received: 9 March 2019; Accepted: 26 March 2019; Published: 31 March 2019

\begin{abstract}
The performance of conventional direct torque control strategy from the viewpoint of flux and torque ripples has been unsatisfactory. Therefore, this study aims to propose a novel finite-control-set model predictive direct torque control strategy with extended output based on two-step prediction. An appropriate pre-selected vector, which is modulated in a specific manner, is selected through a look-up table and then used to optimise the pre-selected voltage vector based on the computing result from the model prediction and output it. The proposed strategy extends the range of the vectors that can be used to enhance the flux and torque control performance and reduce ripples and computational complexity in comparison with the conventional finite-control-set model predictive direct torque control. The feasibility of the proposed method is verified by conducting a verification test using dSPACE and Tyhpoon HIL 402 experimental platform.
\end{abstract}

Keywords: permanent magnet synchronous motors; predictive control; ripples reduction; optimised calculation

\section{Introduction}

Recently, some nonlinear and linear controllers of the complex control systems are proved to be successful in various areas [1-3]. Herein, permanent magnet synchronous motors (PMSMs), as one of the staple applications in the field of motor control, are widely used in high-precision controlled drive systems $[4,5]$ owing to their simple structure, high power density, and excellent dynamic performance [6], for instance electric vehicles [7]. Therefore, high-performance control strategies are crucial for the smooth functioning of PMSMs. Conventional control methods are divided into field-oriented control (FOC) and direct torque control (DTC) methods. FOC method has high-precision and good stability; however, it is more complicated, and its response speed is slower than that of the DTC method [8]. Currently, DTC is being widely applied as a quick-response control strategy using electromagnetic torque and flux as the control target [9-13]. DTC has a simple structure, low computational complexity, and quick-response time. However, the control effect is not good owing to the limitation of flux and torque ripples [14]. Therefore, it is necessary to overcome these limitations.

With the development of microprocessors, model predictive control has gradually been introduced into the permanent magnet synchronous motor torque control and is being developed into the model predictive DTC (MPDTC) method. This method has attracted considerable attention because it can be used to intuitively express the state of important variables and to optimise output; therefore, helping to effectively reduce ripples in the output torque [15-22]. The finite-control-set MPDTC (FCS-MPDTC) 
is a novel torque control strategy, which can effectively predict the state of flux and torque under a limited switching state of the voltage source inverter (VSI). This strategy selects an optimal switching state to apply on the control target, minimising ripples in the torque and flux using a cost function with a reasonable weighting factor [17]. The cost function contains several control targets as a criterion for selecting an optimal voltage space vector (VSV), which intuitively reflects on the control cost. The optimal vector is selected via calculation in each cycle. If the range of output VSVs is limited to eight basic VSVs, there can still be large flux and torque ripples [23]. However, if the number of VSVs is increased, the computational complexity will increase, and the same applies to the computational cost of the processor, which can hamper real-time operation performance.

DTC based on duty cycle modulation improves the steady-state characteristics of flux and torque and reduces ripples. The idea was later introduced in the design of FCS-MPDTC. The algorithm was simplified through a qualitative analysis of the extended 20 modulated VSVs [24]. After observing the flux, predictive calculations are performed on the pre-selected VSVs and the optimal VSV is selected based on the results obtained to improve flux and torque control performance. In this method, the finite set contains 20 different VSVs, and six VSVs are used in performing evaluations in each cycle. In comparison with the conventional torque control strategy, the proposed strategy has positive effects on flux and torque control performance, computational efficiency, and phase current THD. A novel hybrid control system was proposed based on PMSM-driven predictive finite state control strategy [25]. After ignoring the stator resistance voltage drop, the optimal VSV is determined using a cost function with the smallest number of control targets. This method simplifies the algorithm while optimising flux and torque performance. It also achieves good results in reducing the stator phase current THD. Therefore, it is necessary to improve the control performance of the target motor and reduce the computational complexity of the model prediction.

This study proposes a control strategy based on FCS-MPDTC. The effects of active VSVs modulated in a specific manner on the control target are analysed. A control switching table for selecting a pre-selected VSV included in model prediction calculation is thus designed to reduce the number of prediction vectors, which lessens the computational burden. Then, based on deviation result of the target variables with respect to the reference value, the VSV output is adjusted to increase the number of VSVs, which can be outputted to 30, thereby achieving a more accurate and stable torque control. Furthermore, measurement and calculation delays in real-time control are considered in the calculation process of the model prediction. Herein, a novel comprehensive experimental platform for dSPACE and Tyhpoon HIL 402 is used to validate the proposed control method.

The structure of this paper is as follows. A mathematical model of permanent magnet synchronous motor is discussed in Section 2. The characteristics of conventional FCS-MPDTC are presented in Section 3. The principle of operation of the proposed novel DTC strategy is presented in Section 4 . Verification of performance of the proposed method based on the simulations conducted is presented in Section 5. A comprehensive experimental platform based on dSPACE and Typhoon HIL 402 is also established in Section 5 to verify the feasibility of the proposed control method.

\section{Mathematical Model of PMSM}

In the stationary $\alpha-\beta$ coordinate system, the mathematical model of PMSM can be described as:

$$
\begin{gathered}
\frac{\mathrm{d} \boldsymbol{i}_{s}}{\mathrm{dt}}=\frac{1}{L_{s}}\left(\boldsymbol{u}_{s}-R_{s} \boldsymbol{i}_{s}-\mathrm{j} \omega_{e} \boldsymbol{\psi}_{s}\right) \text { and } \\
\frac{\mathrm{d} \boldsymbol{\psi}_{s}}{\mathrm{dt}}=\boldsymbol{u}_{s}-R_{s} \boldsymbol{i}_{s},
\end{gathered}
$$

where $\boldsymbol{i}_{s}$ denotes the stator current, $L_{S}$ denotes the stator inductance, $\boldsymbol{u}_{S}$ denotes the stator voltage, $R_{S}$ denotes the stator resistance, $\omega_{e}$ denotes the electrical angular velocity of the motor, and $\psi_{s}$ denotes the stator flux. 
The torque equation of PMSM can be expressed as:

$$
\begin{gathered}
T_{e}=1.5 p \boldsymbol{\psi}_{s} \otimes \boldsymbol{i}_{s} \text { or } \\
T_{e}=1.5 p\left(\frac{\boldsymbol{\psi}_{f}}{L_{d}}\left|\boldsymbol{\psi}_{s}\right| \sin \delta-\frac{L_{q}-L_{d}}{L_{d} L_{q}}\left|\boldsymbol{\psi}_{s}\right|^{2} \sin \delta \cos \delta\right),
\end{gathered}
$$

where $T_{e}$ denotes the electromagnetic torque, $p$ denotes the pole pair of the motor, $\otimes$ refers to cross product, $L_{d}$ and $L_{q}$ denotes the direct and quadrature stator inductance, $\delta$ denotes the angle between the stator flux and the rotor flux.

For the surface-mount three-phase PMSM, the stator inductance $L_{d}=L_{q}=L_{s}$ at time $T_{e}(4)$ can be expressed as:

$$
\begin{gathered}
T_{e}=\frac{3}{2} \frac{p}{L_{s}}\left|\psi_{s}\right| \psi_{f} \sin \delta \text { and } \\
\frac{d \omega_{e}}{\mathrm{dt}}=\frac{p}{J}\left(T_{e}-T_{L}-B \omega_{m}\right),
\end{gathered}
$$

where $J$ denotes the moment of inertia, $T_{L}$ denotes the load torque, $B$ denotes the viscous friction coefficient of the rotor, and $\omega_{m}$ indicates the mechanical angular velocity of the motor.

\section{Structure and Characteristics of the Conventional FCS-MPDTC}

\subsection{Structure of the Conventional FCS-MPDTC}

FCS-MPDTC is an application of MPC to direct torque control to enhance its conventional DTC and improve motor flux and torque control performance [26]. The strategy can fully utilize the discrete nature of the inverter's switching state. The six active VSVs and the two zero vectors that the inverter can output are used and the optimal VSV that has the lowest cost is selected as the output using the cost function, which is then applied to the control target. The structure of the conventional FCS-MPDTC is shown in Figure 1. FCS-MPDTC can be divided into the following steps: (1) variable measurement; (2) flux estimation and model prediction; (3) cost evaluation and (4) inverter output. Herein, the stator voltage needs to be observed for estimating flux. The voltage states under the action of each switching state are shown in Table 1.

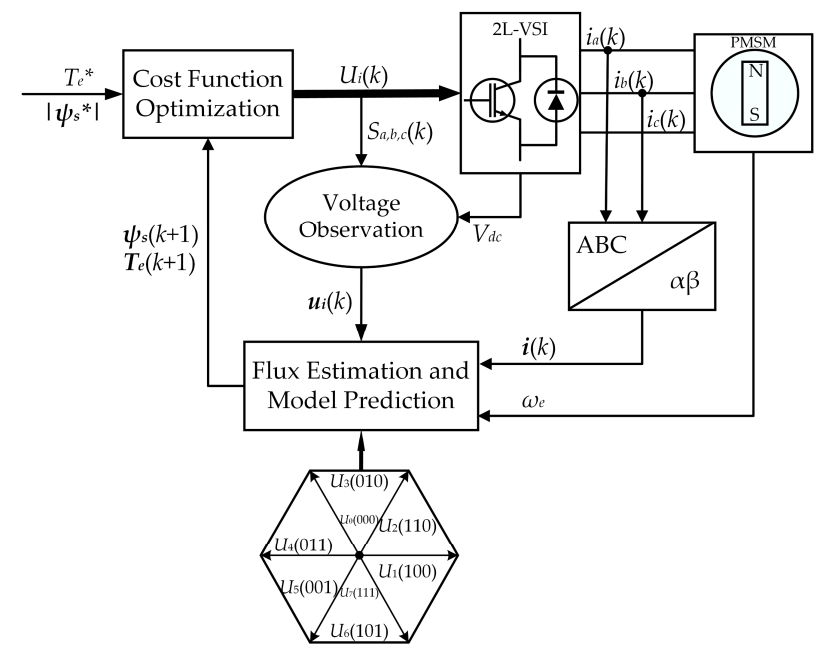

Figure 1. Structure of a conventional FCS-MPDTC.

In the control strategy, the two-phase current on the stator of the motor is required to measure and accurately predict the possible state of the PMSM when VSVs are about to be applied. The mathematical 
model described in Section 2 can be discretised using first-order Forward Euler's formula for the calculation of model prediction as follows:

$$
\begin{gathered}
\boldsymbol{i}_{S}(k+1)=\boldsymbol{i}_{S}(k)+\frac{T_{S}}{L_{S}} \boldsymbol{u}_{s}(k)-R_{S} \boldsymbol{i}_{s}(k)-\mathrm{j} \omega_{e} \boldsymbol{\psi}_{s}(k), \\
\boldsymbol{\psi}_{s}(k+1)=\boldsymbol{\psi}_{s}(k)+T_{S}\left[\boldsymbol{u}_{S}(k)-R_{S} \boldsymbol{i}_{S}(k)\right] .
\end{gathered}
$$

According to Equations (7) and (8), the electromagnetic torque of PMSM at time $k+1$ can be expressed as:

$$
T_{e}(k+1)=1.5 p i_{s}(k+1) \otimes \boldsymbol{\psi}_{s}(k+1) .
$$

Table 1. State of VSVs of the conventional FCS-MPDTC.

\begin{tabular}{cccc}
\hline $\boldsymbol{U}_{\mathbf{x}}$ & $\boldsymbol{S}_{\boldsymbol{a}, \boldsymbol{b}, \boldsymbol{c}}$ & $\mathbf{U}_{\boldsymbol{\alpha}}$ & $\mathbf{U}_{\boldsymbol{\beta}}$ \\
\hline$U_{0}$ & {$\left[\begin{array}{lll}0 & 0 & 0\end{array}\right]$} & 0 & 0 \\
$U_{1}$ & {$\left[\begin{array}{lll}1 & 0 & 0\end{array}\right]$} & $\frac{2}{3} V_{d c}$ & 0 \\
$U_{2}$ & {$\left[\begin{array}{lll}1 & 1 & 0\end{array}\right]$} & $\frac{1}{3} V_{d c}$ & $\frac{\sqrt{3}}{3} V_{d c}$ \\
$U_{3}$ & {$\left[\begin{array}{lll}0 & 1 & 0\end{array}\right]$} & $-\frac{1}{3} V_{d c}$ & $\frac{\sqrt{3}}{3} V_{d c}$ \\
$U_{4}$ & {$\left[\begin{array}{lll}0 & 1 & 1\end{array}\right]$} & $-\frac{2}{3} V_{d c}$ & 0 \\
$U_{5}$ & {$\left[\begin{array}{lll}0 & 0 & 1\end{array}\right]$} & $-\frac{1}{3} V_{d c}$ & $-\frac{\sqrt{3}}{3} V_{d c}$ \\
$U_{6}$ & {$\left[\begin{array}{lll}1 & 0 & 1\end{array}\right]$} & $\frac{1}{3} V_{d c}$ & $-\frac{\sqrt{3}}{3} V_{d c}$ \\
$U_{7}$ & {$\left[\begin{array}{lll}1 & 1 & 1\end{array}\right]$} & 0 & 0 \\
\hline
\end{tabular}

Since the time constant of the rotor is much higher than the sampling time per cycle and the rotor flux action is much slower than the stator flux action, it is assumed that $\omega_{e}(k)=\omega_{e}(k+1)$. The FCS-MPDTC requires estimating the stator flux $\psi_{s}(k)$ and the electromagnetic torque $T_{e}(k)$ based on the measured values of the current $i_{s}(k)$ and the angular velocity $\omega_{e}(k)$. Furthermore, it is critical to ensure that the appropriate cost function is designed to evaluate the predicted result of flux $\psi_{s}(k+1)$ and torque $T_{e}(k+1)$ generated by each VSV $\boldsymbol{u}_{s}(k)$, and to select the optimal voltage based on the result obtained. The VSV acts on the next cycle. The cost function is designed in such a way that the flux and torque always track the specified value. When the value of the cost function is minimum, the currently selected VSV is the optimal VSV that will act in the next cycle. It is usually expressed as:

$$
\operatorname{ming}_{i}=\left|T_{e}^{*}-T_{e}(k+1)\right|+\lambda\left|\psi_{s}^{*}\right|-\left|\psi_{s}(k+1)\right|+I_{l}
$$

where $T_{e}^{*}$ denotes the electromagnetic torque reference value, $\psi_{s}^{*}$ denotes the flux reference value and $\lambda$ denotes the weighting factor that determines the relative importance of stator flux and torque. The choice of weighting factor $\lambda$ depends on the specific application, and there are no exact criteria for function design. It is possible to refer to the output torque range, and the corresponding flux range, as well as the trade-offs between dynamic characteristics of torque and flux in the application. Generally, $\lambda$ is selected to be $T_{n} / \psi_{n}$, where $T_{n}$ and $\psi_{n}$ are the rated values of torque and stator flux, respectively. And $I_{l}$ is included in it on the basis of maximum current capacity $\left(I_{m}\right)$ of the stator winding as follows:

$$
I_{l}= \begin{cases}\infty, & \left|\boldsymbol{i}_{s}(k+1)\right|>I_{m} \\ 0, & \text { otherwise }\end{cases}
$$

\subsection{Characteristics of the Conventional FCS-MPDTC}

First, only eight basic VSVs are introduced in the range that can be evaluated and outputted by the conventional FCS-MPDTC. This limits the control performance and all VSVs are needed per evaluation. If the number of vectors is increased to improve the performance, the computational complexity becomes very high. 
Second, if the average switching frequency $\overline{\mathrm{f}}_{s w}$ [27] and the common-mode voltages $\mathrm{CMV}_{\mathrm{s}}[28]$ are included in the cost function of the conventional FCS-MPDTC, the control target in the cost function will increase. It will be difficult to set weighting factors and the design of a cost function in such a situation would be complicated. Generally, in order to achieve a balance between steady-state torque fluctuations and switching times, an item on the average switching frequency is introduced into the function. However, the meaning of the coefficient (weighting factor) of the switching frequency is not very clear, so it is necessary to make repeated adjustments. In other words, the traditional method to obtain the flux trajectory between the circumference and the hexagon does not intuitively indicate what the coefficient of the frequency term should be. This also makes the design of the cost function involving multiple targets more difficult.

\section{Principle of Operation of the Proposed FCS-MPDTC}

Herein, in order to overcome the limitation of the conventional FCS-MPDTC, a novel FCS-MPDTC is proposed. Six VSVs modulated in a specific manner are used in the evaluation of the model prediction in the proposed FCS-MPDTC. Before calculating the model prediction, a vector switching table is used to determine the VSV included in the calculation and the selected VSV is adjusted according to the deviation of the control target used in the model prediction. In addition, a time delay needs to be considered in the real-time operation of the actual control system. The structure of the proposed control strategy is shown in Figure 2.

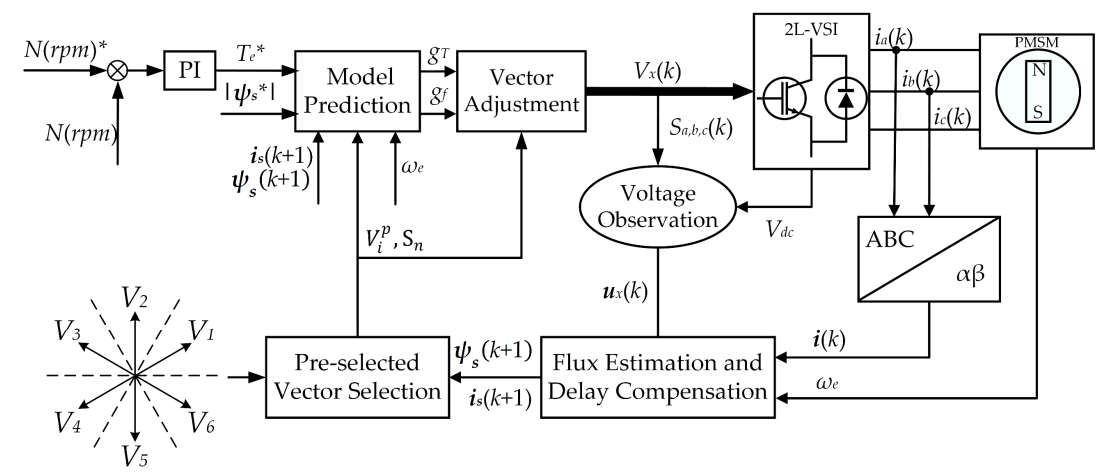

Figure 2. Proposed control system.

\subsection{Pre-selected VSVS}

As shown in Figure 3, six VSVs, $V_{1}-V_{6}$, are used in the proposed control strategy. However, not all the six VSVs are used in evaluating the model prediction. Each of the VSVs is modulated by two fixed duty cycles adjacent to the basic active VSVs, as shown in Table 2. In addition, to determine the position angle of the stator flux $\psi_{s}$, it is necessary to divide the sector along the plane of the $\alpha-\beta$ coordinate axis. The position angle of the stator flux $\psi_{s}$ can be expressed as:

$$
\theta_{s}=\arctan \left(\frac{\theta_{\beta s}}{\theta_{\alpha s}}\right)
$$

In the two-phase stationary coordinate system $(\alpha-\beta)$, the active VSVs of two-level VSI (2L-VSI) are periodically changed by $\pi / 3$, and the coordinate plane can be divided into six sectors, as shown in Table 3. This can be expressed as:

$$
\frac{\pi}{3}(\mathrm{n}-1)<S_{\mathrm{n}}<\frac{\pi}{3} \mathrm{n} .
$$

The stator flux is located in the sector $S_{\mathrm{n}}, \mathrm{n} \in\{1, \ldots, 6\}$. 


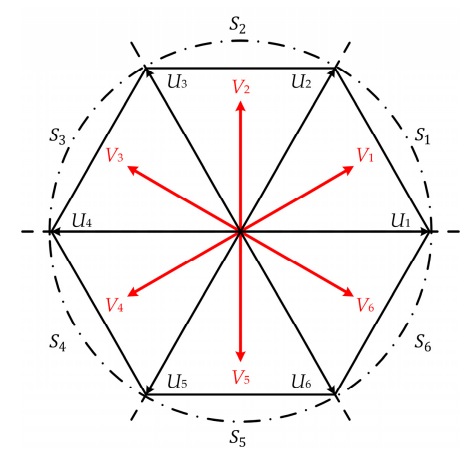

Figure 3. VSVs involved.

Table 2. VSVs in $\alpha-\beta$ Planar.

\begin{tabular}{cc}
\hline Vector & Modulated by \\
\hline$V_{1}$ & $0.4\left(U_{1}+U_{2}\right)$ \\
$V_{2}$ & $0.4\left(U_{2}+U_{3}\right)$ \\
$V_{3}$ & $0.4\left(U_{3}+U_{4}\right)$ \\
$V_{4}$ & $0.4\left(U_{4}+U_{5}\right)$ \\
$V_{5}$ & $0.4\left(U_{5}+U_{6}\right)$ \\
$V_{6}$ & $0.4\left(U_{6}+U_{1}\right)$ \\
\hline
\end{tabular}

Table 3. Sector division in $\alpha-\beta$ Planar.

\begin{tabular}{ccccccc}
\hline$\theta_{s}$ & $0 \sim \frac{1}{3} \pi$ & $\frac{1}{3} \pi \sim \frac{2}{3} \pi$ & $\frac{2}{3} \pi \sim \pi$ & $\pi \sim \frac{4}{3} \pi$ & $\frac{4}{3} \pi \sim \frac{5}{3} \pi$ & $\frac{5}{3} \pi \sim 2 \pi$ \\
\hline $\mathrm{n}$ & 1 & 2 & 3 & 4 & 5 & 6 \\
\hline
\end{tabular}

\subsection{VSVs Involved in the Calculation of Model Prediction}

Herein, a DTC switching table is used to select VSVs that are used in evaluating the model prediction. Using the deviation of the flux and torque, the flux and torque increase and decrease signals can be obtained. Combined with the sector where the stator flux is located, the VSV used in calculating the model prediction can be selected. After applying the VSVs shown in Table 2, different effects are generated on the motor. Taking the stator flux in the $S_{1}$ sector as an example, the control effect of each VSV on the flux and torque is analysed, as shown in Figure 4. Assuming the motor rotates in a counterclockwise direction, there will be $\theta_{s} \in\left(0 \sim \frac{1}{3} \pi\right)$ at this time.

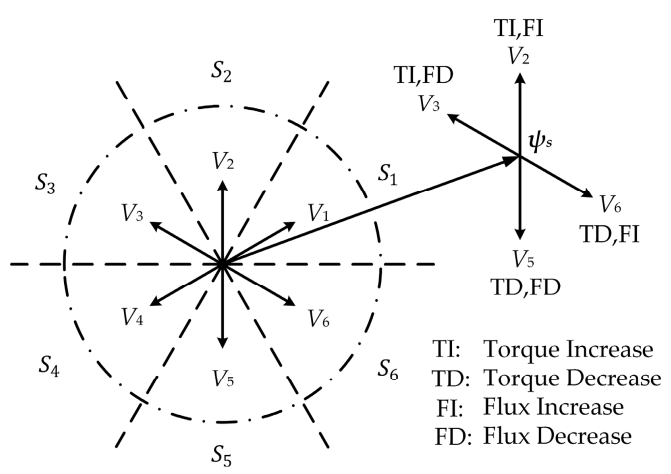

Figure 4. The effect of applying VSVs.

It can be seen from Figure 4 that when the stator flux is at $S_{1}$, the VSVs $V_{2}$ or $V_{3}$ acts on the inverter to increase the torque, whereas $V_{5}$ or $V_{6}$ can lead to a reduction in the torque. The VSV $V_{2}$ or $V_{6}$ acts on the inverter to increase the flux, whereas $V_{3}$ or $V_{5}$ can lead to a reduction of the flux. When the stator flux is in other sectors, the analysis of the control effect can analogise similarly. The torque control 
switching table used in this strategy is shown in Table 4, where the flux deviation can be expressed as $\delta \psi_{s}=\left|\psi_{s}^{*}\right|-\left|\psi_{s}\right|$, and the torque deviation as $\delta T_{e}=T_{e}^{*}-T_{e}$. At a certain point, the stator flux would be in a certain sector in the plane, $\delta \psi_{s}>0$ denotes the flux increase signal, $\delta \psi_{s}<0$ denotes the flux reduction signal and the torque increase or decrease signal also behaves in a similar manner. Based on the proposed FCS-MPDTC strategy, the selected VSV is included in the calculation of model prediction. There is only one VSV included in the calculation per cycle and the computing time is reduced by $23 \%$ compared with the conventional FCS-MPDTC.

Table 4. Torque control switching table.

\begin{tabular}{cccccccc}
\hline$\delta \psi_{s}$ & $\delta \boldsymbol{T}_{\boldsymbol{e}}$ & $\boldsymbol{S}_{\mathbf{1}}$ & $\boldsymbol{S}_{\mathbf{2}}$ & $\boldsymbol{S}_{\mathbf{3}}$ & $\boldsymbol{S}_{\mathbf{4}}$ & $\boldsymbol{S}_{5}$ & $\boldsymbol{S}_{\mathbf{6}}$ \\
\hline \multirow{2}{*}{$\delta \psi_{s}>0$} & $\delta T_{e}>0$ & $V_{2}$ & $V_{3}$ & $V_{4}$ & $V_{5}$ & $V_{6}$ & $V_{1}$ \\
& $\delta T_{e}<0$ & $V_{6}$ & $V_{1}$ & $V_{2}$ & $V_{3}$ & $V_{4}$ & $V_{5}$ \\
\hline \multirow{2}{*}{$\delta \psi_{s}<0$} & $\delta T_{e}>0$ & $V_{3}$ & $V_{4}$ & $V_{5}$ & $V_{6}$ & $V_{1}$ & $V_{2}$ \\
& $\delta T_{e}<0$ & $V_{5}$ & $V_{6}$ & $V_{1}$ & $V_{2}$ & $V_{3}$ & $V_{4}$ \\
\hline
\end{tabular}

\subsection{Delay Compensation}

A large number of calculations are required when multiple information sampling and complex control method like FCS-MPDTC are implemented [29]. The digital control in the actual system has a one-step control delay when performing a real-time calculation, so that the optimal VSV selected in the current sampling period cannot be applied to the system until the next cycle. Therefore, this would affect the control performance and will require one-step delay compensation [16]. It is done by a two-step ahead prediction [30]. The one-step prediction is used to compensate the time delay and another one-step prediction is used to predict the control effect of the flux and torque after the VSV is about to be applied. According to Equations (7)-(9), the flux $\psi_{s}(k+1)$ and torque $T_{e}(k+1)$ after the compensation of time delay are used to calculate the deviation values $\delta \psi_{s}$ and $\delta T_{e}$ that are used in selecting the pre-selected VSV included in the model prediction. Furthermore, the flux $\psi_{s}(k+1)$ and the stator current $i_{s}(k+1)$ are used in calculating the model prediction as the initial state at the time instant $k+2$. The stator current and flux equations after the delay compensation are as follows:

$$
\begin{gathered}
\boldsymbol{i}_{S}(k+2)=\boldsymbol{i}_{S}(k+1)+\frac{T_{S}}{L_{s}}\left[\boldsymbol{u}_{s}(k+1)-R_{s} \boldsymbol{i}_{S}(k+1)-\mathrm{j} \omega_{e} \boldsymbol{\psi}_{s}(k+1)\right] \text { and } \\
\boldsymbol{\psi}_{s}(k+2)=\boldsymbol{\psi}_{s}(k+1)+T_{S}\left[\boldsymbol{u}_{s}(k+1)-R_{s} \boldsymbol{i}_{S}(k+1)\right] .
\end{gathered}
$$

According to Equations (9), (14) and (15), the electromagnetic torque can be expressed as:

$$
T_{e}(k+2)=1.5 p i_{s}(k+2) \otimes \boldsymbol{\psi}_{s}(k+2) .
$$

\subsection{Adjustment of the Pre-Selected VSV}

If the VSV that is applied to the inverter has only six VSVs, as shown in Table 2, it is undoubtedly similar to the conventional DTC. Although the structure is simple and the operation speed is fast, there would be large flux and torque ripples, which affects the control effect of the motor. Therefore, to reduce the flux and torque ripples, the proposed control strategy adjusts the VSV to be the output with respect to the deviation of $\psi_{s}(k+2)$ and $T_{e}(k+2)$, calculated using Equations (14)-(16). The extended VSVs for adjustment are shown in Table 5 . The flux deviation can be expressed as:

$$
g_{f}=\left|\psi_{s}^{*}\right|-\left|\psi_{s}(k+2)\right| .
$$

The torque deviation can be expressed as:

$$
g_{T}=T_{e}^{*}-T_{e}(k+2) .
$$


Table 5. Modulation of the extended VSVs.

\begin{tabular}{cccccc}
\hline Vector & \multicolumn{4}{c}{ Modulation of Extended VSVs } \\
\hline \multirow{2}{*}{$V_{1}$} & $V_{11}$ & $V_{12}$ & $V_{13}$ & $V_{14}$ & $V_{15}$ \\
& $0.4\left(U_{1}+U_{2}\right)$ & $0.5\left(U_{1}+U_{2}\right)$ & $0.3\left(U_{1}+U_{2}\right)$ & $0.08 U_{1}+0.72 U_{2}$ & $0.72 U_{1}+0.08 U_{2}$ \\
\cline { 2 - 6 }$V_{2}$ & $V_{21}$ & $V_{22}$ & $V_{23}$ & $V_{24}$ & $V_{25}$ \\
& $0.4\left(U_{2}+U_{3}\right)$ & $0.5\left(U_{2}+U_{3}\right)$ & $0.3\left(U_{2}+U_{3}\right)$ & $0.08 U_{2}+0.72 U_{3}$ & $0.72 U_{2}+0.08 U_{3}$ \\
\hline \multirow{2}{*}{$V_{3}$} & $V_{31}$ & $V_{32}$ & $V_{33}$ & $V_{34}$ & $V_{35}$ \\
& $0.4\left(U_{3}+U_{4}\right)$ & $0.5\left(U_{3}+U_{4}\right)$ & $0.3\left(U_{3}+U_{4}\right)$ & $0.08 U_{3}+0.72 U_{4}$ & $0.72 U_{3}+0.08 U_{4}$ \\
\hline \multirow{2}{*}{$V_{4}$} & $V_{41}$ & $V_{42}$ & $V_{43}$ & $V_{44}$ & $V_{45}$ \\
& $0.4\left(U_{4}+U_{5}\right)$ & $0.5\left(U_{4}+U_{5}\right)$ & $0.3\left(U_{4}+U_{5}\right)$ & $0.08 U_{4}+0.72 U_{5}$ & $0.72 U_{4}+0.08 U_{5}$ \\
\hline \multirow{2}{*}{$V_{5}$} & $V_{51}$ & $V_{52}$ & $V_{53}$ & $V_{54}$ & $V_{55}$ \\
& $0.4\left(U_{5}+U_{6}\right)$ & $0.5\left(U_{5}+U_{6}\right)$ & $0.3\left(U_{5}+U_{6}\right)$ & $0.08 U_{5}+0.72 U_{6}$ & $0.72 U_{5}+0.08 U_{6}$ \\
\hline \multirow{2}{*}{$V_{6}$} & $V_{61}$ & $V_{62}$ & $V_{63}$ & $V_{64}$ & $V_{65}$ \\
& $0.4\left(U_{1}+U_{6}\right)$ & $0.5\left(U_{1}+U_{6}\right)$ & $0.3\left(U_{1}+U_{6}\right)$ & $0.08 U_{1}+0.72 U_{6}$ & $0.72 U_{1}+0.08 U_{6}$ \\
\hline
\end{tabular}

The purpose of the adjustment is to extend the range of the finite set of the output VSV, which enhances the tracking ability of the stator flux and the electromagnetic torque in the control system to reduce the flux and torque ripples. For instance, at a specific moment, the stator flux is in the $S_{1}$ sector, at which time $\delta \psi_{s}>0, \delta T_{e}>0$ and the VSV $V_{2}$ to be outputted is selected from Table 4. According to Equations (14)-(16), the flux and torque after $V_{2}$ is about to be applied to the inverter are predicted to be $\psi_{s}(k+2)$ and $T_{e}(k+2)$, respectively. At this point, the predicted flux deviation value $g_{f}$ has three possibilities, $g_{f}>0, g_{f}<0$ and $g_{f}=0$, and the predicted torque deviation value may be $g_{T}>0$, $g_{T}<0$ and $g_{T}=0$. According to the signs of $g_{f}$ and $g_{T}$, the effect of the pre-selected VSV $V_{2}$ can be known. $g_{f}>0$ indicates that the sign of deviation value is still positive after the VSV is applied and the flux amplitude needs to be increased. $g_{f}<0$ indicates that the amplitude is increased excessively and the pre-selected VSV needs to be adjusted to reduce the extent of flux magnitude increase. $g_{f}=0$ implies that the flux has reached the reference value after the pre-selected VSV is about to be applied. $g_{T}>0$ implies that the torque still needs to be increased after the VSV is applied. $g_{T}<0$ implies that the torque needs to be reduced based on the extent of torque increase. $g_{T}=0$ implies that the torque is already equal to the reference value. The pre-selected VSV is adjusted according to the sector and the prediction of the stator flux, as shown in Figure 5.

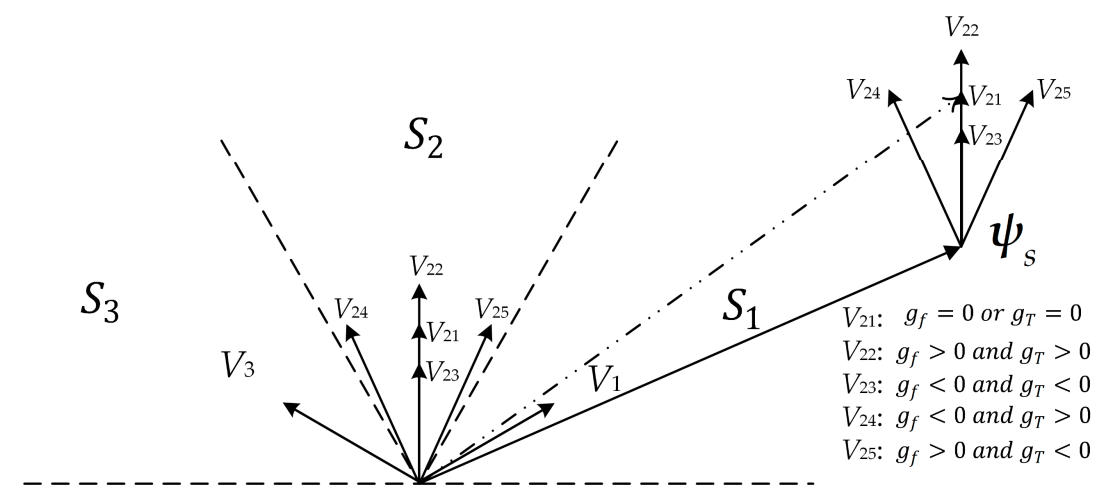

Figure 5. Adjustment of the pre-selected VSV when the stator flux position is in $S_{1}$.

To reduce the complexity of the control algorithm, this paper designs and adjusts the control table of the pre-selected VSV based on the control switching table for the conventional DTC [9] strategy. The adjustment of the VSVs $V_{1}-V_{2}$ is as shown in Table 6 and the VSVs $V_{3}-V_{6}$ can be explained in line with the above analysis. 
Table 6. The adjustment table of the pre-selected VSV.

\begin{tabular}{|c|c|c|c|c|c|c|}
\hline Vector & $g_{f}$ & $g_{T}$ & $S_{2}$ & $S_{3}$ & $S_{5}$ & $S_{6}$ \\
\hline \multirow{3}{*}{$V_{1}$} & $g_{f}>0$ & $\begin{array}{l}g_{T}>0 \\
g_{T}<0\end{array}$ & $\begin{array}{l}V_{14} \\
V_{12} \\
\end{array}$ & $\begin{array}{l}V_{13} \\
V_{14} \\
\end{array}$ & $\begin{array}{l}V_{15} \\
V_{13} \\
\end{array}$ & $\begin{array}{l}V_{12} \\
V_{15}\end{array}$ \\
\hline & $g_{f}<0$ & $\begin{array}{l}g_{T}>0 \\
g_{T}<0\end{array}$ & $\begin{array}{l}V_{13} \\
V_{15} \\
\end{array}$ & $\begin{array}{l}V_{15} \\
V_{12} \\
\end{array}$ & $\begin{array}{l}V_{12} \\
V_{14} \\
\end{array}$ & $\begin{array}{l}V_{14} \\
V_{13} \\
\end{array}$ \\
\hline & \multicolumn{3}{|c|}{$g_{f}=0$ or $g_{T}=0$} & \multicolumn{2}{|c|}{$V_{11}$} & \\
\hline$V_{\mathrm{x}}$ & $g_{f}$ & $g_{T}$ & $S_{1}$ & $S_{3}$ & $S_{4}$ & $S_{6}$ \\
\hline \multirow[b]{2}{*}{$V_{2}$} & $g_{f}>0$ & $\begin{array}{l}g_{T}>0 \\
g_{T}<0\end{array}$ & $\begin{array}{l}V_{22} \\
V_{25} \\
\end{array}$ & $\begin{array}{l}V_{24} \\
V_{22} \\
\end{array}$ & $\begin{array}{l}V_{23} \\
V_{24} \\
\end{array}$ & $\begin{array}{l}V_{25} \\
V_{23} \\
\end{array}$ \\
\hline & $g_{f}<0$ & $\begin{array}{l}g_{T}>0 \\
g_{T}<0\end{array}$ & $\begin{array}{l}V_{24} \\
V_{23}\end{array}$ & $\begin{array}{l}V_{23} \\
V_{25}\end{array}$ & $\begin{array}{l}V_{25} \\
V_{22}\end{array}$ & $\begin{array}{l}V_{22} \\
V_{24}\end{array}$ \\
\hline
\end{tabular}

The specific steps of the proposed FCS-MPDTC control strategy are summarised as follows:

1. The phase current $i_{s}(k)$, the DC voltage $V_{d c}(k)$, and the electrical angular velocity $\omega_{e}(k)$ are sampled.

2. Apply the VSV $V_{\mathrm{x}}(k)$ to the power device.

3. Estimate the stator flux $\psi_{s}(k)$.

4. The stator current $\boldsymbol{i}_{s}(k+1)$ and the stator flux $\psi_{s}(k+1)$ are predicted for delay compensation.

5. The VSV $V_{\mathrm{x}}(k+1)$ included in the prediction calculation is selected according to Tables 3 and 4 .

6. The VSV selected in the fifth step is predicted. The predicted flux $\psi_{s}(k+2)$ and the predicted torque $T_{e}(k+2)$ are calculated using Equations (14)-(16) and the VSV to be outputted is adjusted and outputted according to the cases of $g_{f}, g_{T}$ and Table 6 .

\section{Simulation and Experiment}

In order to verify the feasibility and control performance of the proposed FCS-MPDTC, relevant simulations and experiments were completed. This paper proposes an experimental approach by using a new comprehensive experimental platform. The control strategy is implemented using dSPACE DS1006 R\&D controller board with ControlDesk and MATLAB/Simulink software packages and Typhoon HIL 402 with digital hardware models. The development process of the simulation and experiment is shown in Figure 6. After the offline simulation based on MATLAB/Simulink is completed by using the developed control strategy, online operation and monitoring are implemented in the established experimental platform.

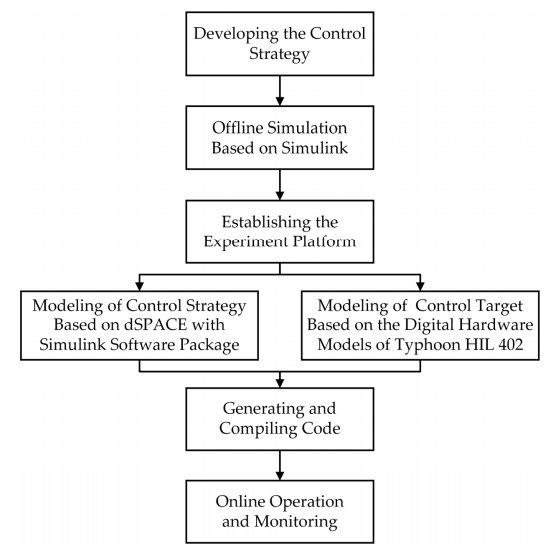

Figure 6. The development process based on the experiment platform. 


\subsection{Simulation}

Herein, the proposed FCS-MPDTC is simulated using MATLAB/Simulink. The parameters of PMSM and the control system are listed in Table 7. All methods have a sampling frequency of $10 \mathrm{kHz}$.

Table 7. Motor and control parameters used in the simulation.

\begin{tabular}{ccc}
\hline Parameters & Symbol & Value \\
\hline Stator resistance & $R_{s}$ & $1.2 \Omega$ \\
Stator inductance & $L_{s}$ & $8.5 \mathrm{mH}$ \\
Permanent magnet flux & $\psi_{f}$ & $0.175 \mathrm{~Wb}$ \\
Number of pole pairs & $p$ & 4 \\
Moment of inertia & $J$ & $0.0008 \mathrm{~kg} \cdot \mathrm{m}^{2}$ \\
Torque limiting & $T_{\lim }$ & $10 \mathrm{~N} \cdot \mathrm{m}$ \\
DC bus voltage & $V_{d c}$ & $311 \mathrm{~V}$ \\
\hline
\end{tabular}

A comparative study of conventional DTC, conventional FCS-MPDTC, and the proposed FCS-MPDTC is shown in Figure 7. The motor was run at $600 \mathrm{rpm}$ and an external load of $1.5 \mathrm{~N} \cdot \mathrm{m}$ was applied at $t=0.2 \mathrm{~s}$. For further comparative analysis, the standard deviation is introduced to measure torque and flux [31]. The formula for evaluating the torque and flux standard deviation can be expressed as:

$$
\begin{gathered}
S_{\mathrm{Te}}=\sqrt{\frac{\sum_{n=1}^{\mathrm{N}}\left(T_{e}(n)-\overline{T_{e}}\right)}{\mathrm{N}} \text { and }} \\
S_{\text {flux }}=\sqrt{\frac{\sum_{n=1}^{\mathrm{N}}\left(\left|\boldsymbol{\psi}_{s}(n)\right|-\left|\overline{\psi_{s}}\right|\right)}{\mathrm{N}}},
\end{gathered}
$$

where $T_{e}(n)$ denotes the torque of the nth sampling point, $\overline{T_{e}}$ denotes the average torque, $\left|\boldsymbol{\psi}_{s}(n)\right|$ denotes the flux amplitude of the nth sampling point, $\left|\psi_{s}\right|$ denotes the average of the flux, and $\mathrm{N}$ denotes the number of sampling points.
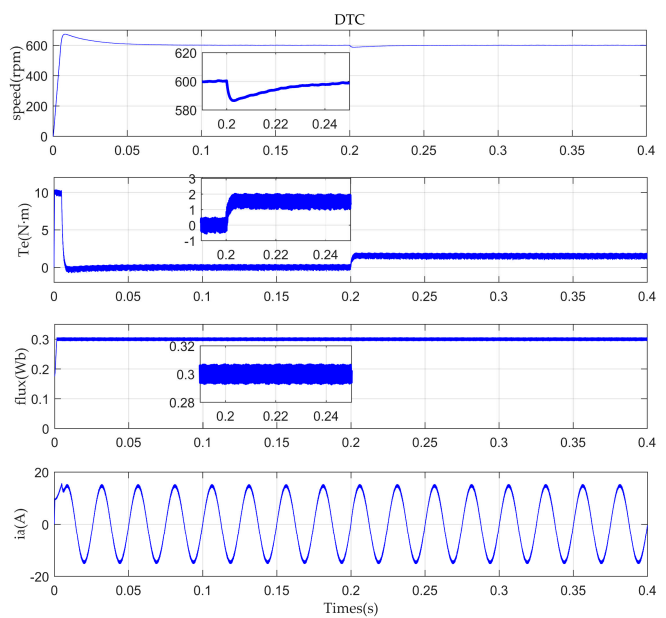

(a)
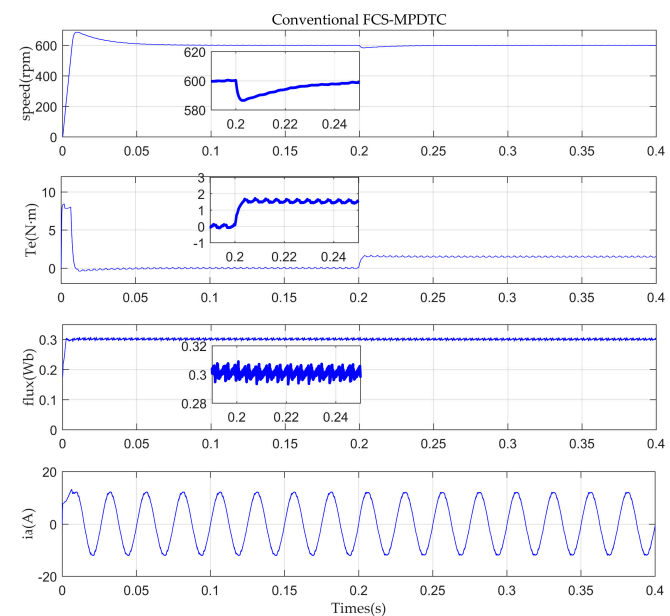

(b)

Figure 7. Cont. 

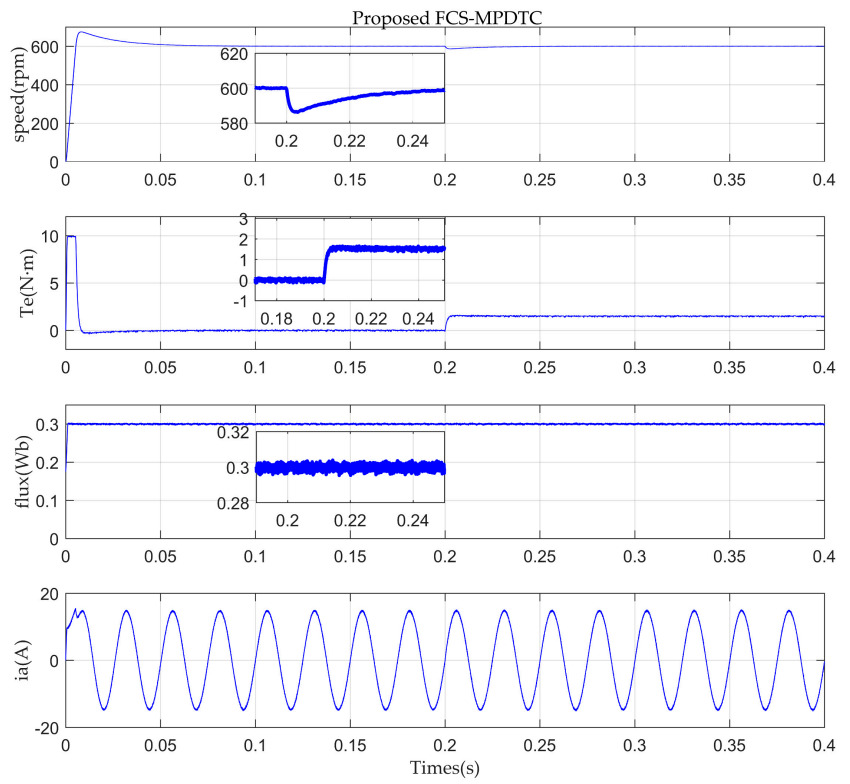

(c)

Figure 7. Simulation of the corresponding speed, torque, flux and stator current at $600 \mathrm{rpm}$ and $1.5 \mathrm{~N} \cdot \mathrm{m}$ load changes. The methods used in generating these signals are: (a) Conventional DTC;

(b) Conventional FCS-DTC and (c) Proposed FCS-MPDTC.

The simulation results show that the conventional DTC torque standard deviation $\left(S_{\mathrm{Te}}\right)$ and flux standard deviation $\left(S_{\text {flux }}\right)$ are higher at steady state, i.e., $0.2761 \mathrm{~N} \cdot \mathrm{m}$ and $0.0035 \mathrm{~Wb}$, respectively. For the conventional FCS-MPDTC, $S_{\mathrm{Te}}$ and $S_{\text {flux }}$ are $0.0668 \mathrm{~N} \cdot \mathrm{m}$ and $0.0020 \mathrm{~Wb}$, respectively, which are lower than those for the conventional DTC. However, the proposed FCS-MPDTC has the best effect. In comparison with the conventional DTC, $S_{\mathrm{Te}}$ and $S_{\text {flux }}$ are reduced by $0.2269 \mathrm{~N} \cdot \mathrm{m}$ and $0.0021 \mathrm{~Wb}$, respectively. Similarly, when compared to the conventional FCS-MPDTC, its $S_{\mathrm{Te}}$ and $S_{\text {flux }}$ are reduced by $0.0176 \mathrm{~N} \cdot \mathrm{m}$ and $0.0006 \mathrm{~Wb}$, respectively.

Additionally, the THD analysis of the A-phase stator current under different control strategies was performed at a simulation time ranging from $0.075 \mathrm{~s}$ to $0.175 \mathrm{~s}$, as shown in Figure 8. The FCS-MPDTC phase current THD in the proposed method is the lowest; it is $1.48 \%$ and $0.21 \%$ lower than the conventional DTC and FCS-MPDTC, respectively. Table 8 shows a quantitative comparison of the steady-state control effects of the three control strategies. Obviously, the proposed FCS-MPDTC torque and flux ripples are significantly reduced, the phase current THD is correspondingly reduced and the motor control performance improved.
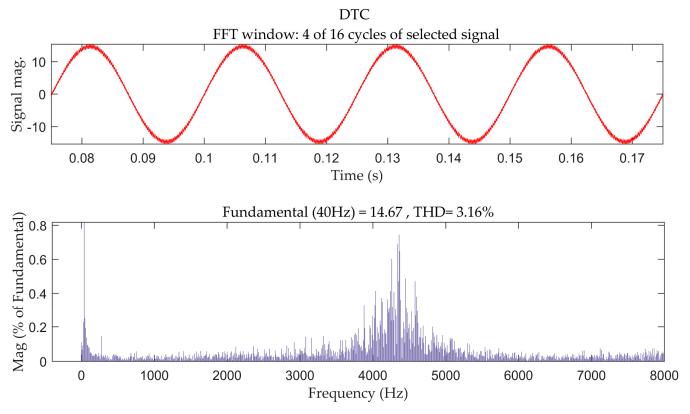

(a)
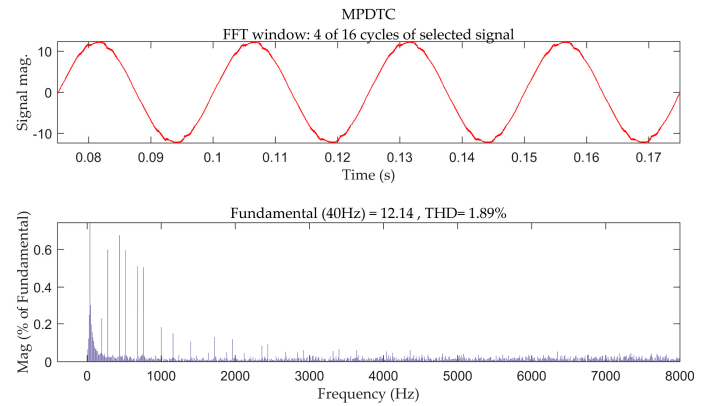

(b)

Figure 8. Cont. 

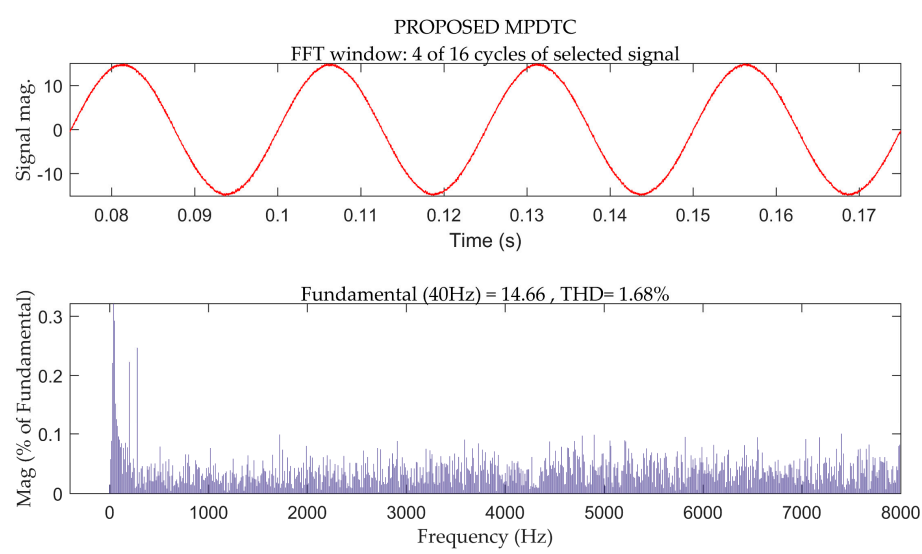

(c)

Figure 8. THD analysis of phase current $i_{a}$. The methods used in generating these signals are: (a) Conventional DTC; (b) Conventional FCS-DTC and (c) Proposed FCS-MPDTC.

Table 8. Comparison of the steady-state control effects of the three control strategies.

\begin{tabular}{cccc}
\hline Strategy & Torque Standard Deviation & Flux Standard Deviation & Phase Current THD \\
\hline DTC & $0.2761 \mathrm{~N} \cdot \mathrm{m}$ & $0.0035 \mathrm{~Wb}$ & $3.16 \%$ \\
Conventional FCS-MPDTC & $0.0668 \mathrm{~N} \cdot \mathrm{m}$ & $0.0020 \mathrm{~Wb}$ & $1.89 \%$ \\
Proposed FCS-MPDTC & $0.0492 \mathrm{~N} \cdot \mathrm{m}$ & $0.0014 \mathrm{~Wb}$ & $1.68 \%$ \\
\hline
\end{tabular}

\subsection{Experiment}

Herein, dSPACE and Tyhpoon HIL 402 were used to build a comprehensive experimental platform for theoretical verification. The dSPACE central processing system used the DS1006 driver board; DS2004 and DS2103 were used for A/D and D/A conversion, respectively, and the control system used DS5202 as the AC speed control board. Since the development of complex power electronics and drive systems is a very time-consuming process, requiring different tools and complex steps [32-36], the hardware Tyhpoon HIL 402 was chosen for the experiment. It is a test platform integrated with high-precision power electronic hardware model, which can simulate the working state of the hardware under actual working conditions and the physical simulation model can be downloaded to the target machine for hardware-in-the-loop (HIL) testing [37]. The integrated hardware experiment platform is shown in Figure 9. The composition of the experimental platform is in turn by the host computer, dSPACE as the controller and Typhoon HIL 402 used as the control object. In the hardware of dSPACE, a DS1006 processor board, a DS5202 FPGA base board and EV1048 signal conditioning hardware (piggy-back) are required for AC Motor Control (ACMC). The controller model designed by the user is executed on the DS1006. The ACMC Real-Time Interface (RTI) block-set is an interface between the DS1006 and the DS5202. After downloading the hardware model of the control target established in the software called Typhoon HIL Control Center to the hardware of Tyhpoon HIL 402, online HIL test can be performed. dSPACE and Tyhpoon HIL 402 can be seamlessly connected through I/O interface. Specific connection settings of the experiment platform are shown as Figure 10. Typhoon HIL 402 has 16 analog I/O interfaces, three of which are used for the acquisition of phase current and DC voltage. In addition, it has 32 digital I/O interfaces, three of which are used for the acquisition of encoder signal and 3/6 of them are used for PWM signals. The hardware interacts with the host computer through ControlDesk and SCADA software.

Besides, the hardware digital models of the control target built in the experimental test is shown in Figure 11. The model consists of three parts: single phase rectification, 2L-VSI and PMSM. After it is finished, it is compiled and built into an executable code for download to the target hardware. The settings for the model parameters and control parameters can be made in the relevant software of Typhoon HIL 402. The specific settings of the parameters are as follows: The DC side voltage $V_{\mathrm{a}}$ 
$=311 \mathrm{~V}$, the stator resistance $R_{\mathrm{S}}=1.2 \Omega$, the stator inductance $L_{\mathrm{s}}=8.5 \times 10^{-3} \mathrm{H}$, the rotor flux $\psi_{f}$ $=0.175 \mathrm{~Wb}$, the number of motor pole pairs $p=4$ and the moment of inertia $\mathrm{J}=8 \times 10^{-4} \mathrm{~kg} \cdot \mathrm{m}^{2}$. Furthermore, the sampling frequency is set to $10 \mathrm{kHz}$, the dead time of the IGBT is set to $5 \mathrm{~s}$, and the motor speed can be outputted and obtained using the internal 1024-pulse incremental encoder.

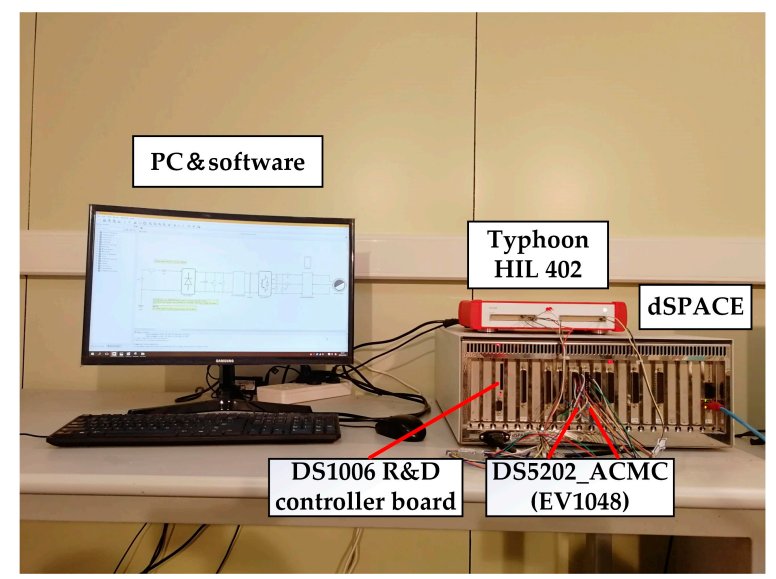

Figure 9. Experiment platform based on dSPACE and Tyhpoon HIL 402.

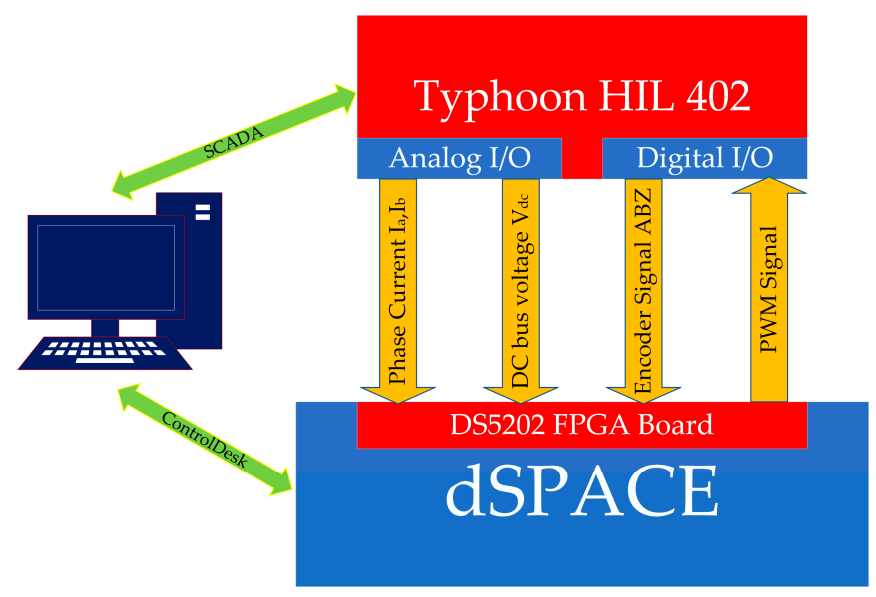

Figure 10. Specific connection settings of the experiment platform.

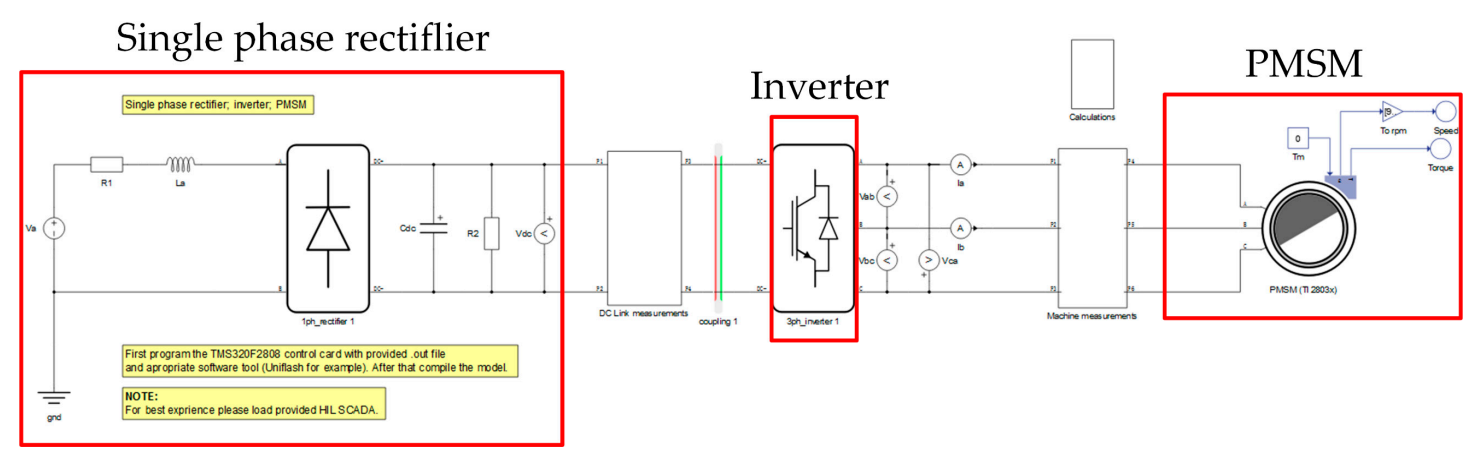

Figure 11. Hardware model based on the software of Tyhpoon HIL 402.

Figure 12 shows the state of the stator flux and the electromagnetic torque during steady-state no-load operation of the motor under three control strategies captured by ControlDesk and SCADA software, respectively. It can be observed from the figure that the conventional DTC strategy flux ranges from $0.28 \mathrm{~Wb}$ to $0.34 \mathrm{~Wb}$, whereas the torque ranges from $-2 \mathrm{~N} \cdot \mathrm{m}$ to $2.5 \mathrm{~N} \cdot \mathrm{m}$. The conventional FCS-MPDTC strategy flux ranges from $0.29 \mathrm{~Wb}$ to $0.31 \mathrm{~Wb}$, whereas the torque ranges from $-1.8 \mathrm{~N} \cdot \mathrm{m}$ 
to $2.0 \mathrm{~N} \cdot \mathrm{m}$. For the proposed FCS-MPDTC, the strategy flux ranges from $0.295 \mathrm{~Wb}$ to $0.31 \mathrm{~Wb}$ and the torque ranges from $-1.2 \mathrm{~N} \cdot \mathrm{m}$ to $1.2 \mathrm{~N} \cdot \mathrm{m}$ with the smallest flux and torque ripples and the best control effect.
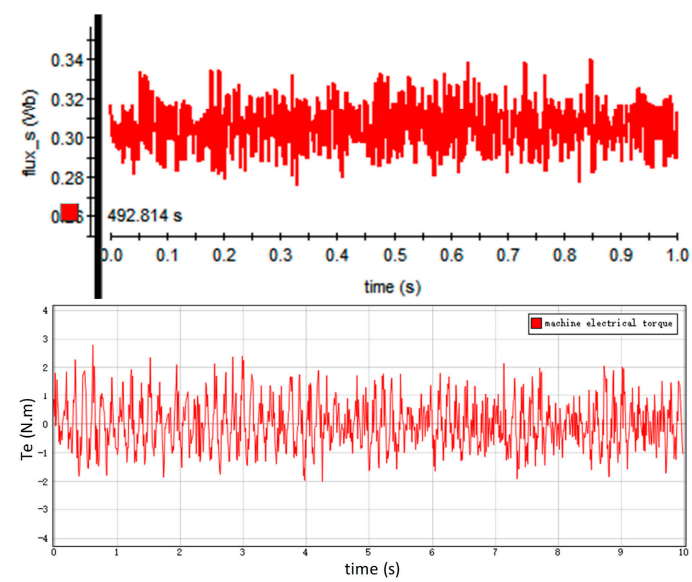

(a)
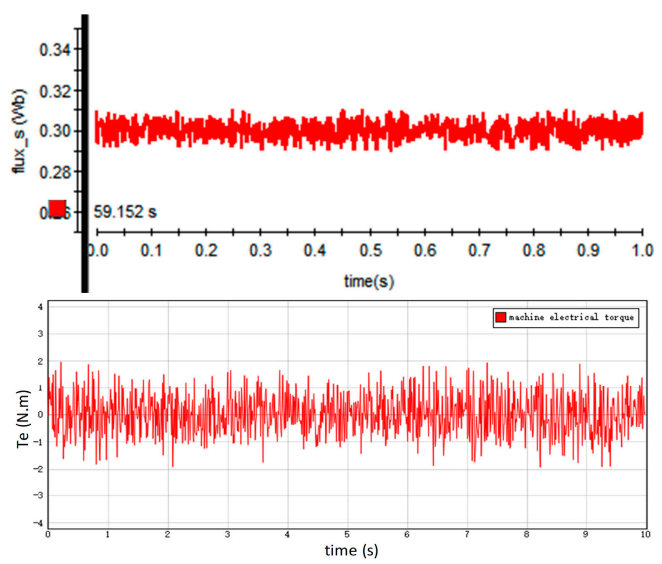

(b)
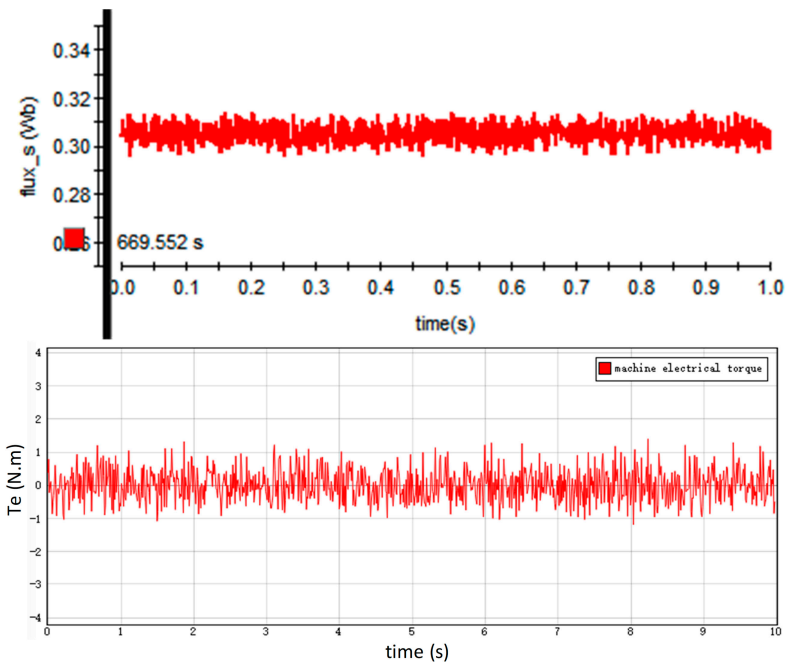

(c)

Figure 12. Experimental steady-state response of flux and torque at no load. The methods used in generating these signals are: (a) Conventional DTC, (b) Conventional FCS-DTC; and (c) Proposed FCS-MPDTC.

\section{Conclusions}

This study presents a novel DTC strategy based on two-step prediction, which can extend the range of output VSVs. In comparison with the conventional FCS-MPDTC, herein, there is no need to introduce a cost function. Based on the analysis of the effects of six VSVs modulated in a specific manner, only one VSV is selected to participate in the evaluation of model prediction at a time, and the pre-selected vector is adjusted and outputted to the power device based on the result of the computation. At the same time, to improve the tracking capability of magnetic flux and torque, the number of vectors that can be outputted is expanded to 30. In comparison with conventional DTC and conventional FCS-MPDTC, the proposed strategy has lower flux and torque ripples as well as lower phase current THD, which improves the steady-state performance of torque and computational efficiency. In addition, the construction and implementation of the new experimental platform can also provide a new reference for the experiment and development of power electronics and drive systems. 
Author Contributions: Guidance of theoretical analysis and writing: M.D.; operation of the experiments, analysis and writing of the paper: Y.T.; guidance of theoretical analysis: W.W.; guidance and optimising of experiments: K.W.; modification of the manuscript: Z.O.

Funding: This research was funded by the "New Energy Vehicle" Key Special Project of the National Key Research and Development Plan, No. 2017YFB0102500 and the Tianjin Natural Science Foundation of China, No. 17JCYBJC21300.

Acknowledgments: The authors thank William Gerard Hurley for dedicating time to review this work. And the authors would like to acknowledge the financial support of the "New Energy Vehicle" Key Special Project of the National Key Research and Development Plan (No. 2017YFB0102500) and the Tianjin Natural Science Foundation of China (No. 17JCYBJC21300).

Conflicts of Interest: The authors declare no conflict of interest.

\section{References}

1. Barut, M.; Bogosyan, S.; Gokasan, M. Experimental evaluation of braided EKF for sensorless control of induction motors. IEEE Trans. Ind. Electron. 2008, 55, 620-632. [CrossRef]

2. Precup, R.; Preitl, S.; Petriu, E.M.; Tar, J.K.; Tomescu, M.L.; Pozna, C. Generic two-degree-of-freedom linear and fuzzy controllers for integral processes. J. Frankl. Inst. 2009, 346, 980-1003. [CrossRef]

3. Vrkalovic, S.; Lunca, E.-C.; Borlea, I.-D. Model-free sliding mode and fuzzy controllers for reverse osmosis desalination plants. Int. J. Artif. Intell. 2018, 16, 208-222.

4. Wei, K.; Du, M.; Xie, L. Study of bonding wire failure effects on external measurable signals of IGBT module. IEEE Trans. Device Mater. Reliab. 2014, 14, 83-89.

5. An, N.; Du, M.; Hu, Z.; Wei, K. Model for Monitoring of Temperature Variations in Insulated Gate Bipolar Transistor (IGBT) Modules. Energies 2018, 11, 595. [CrossRef]

6. Kivanc, O.C.; Ozturk, S.B. Sensorless PMSM Drive Based on Stator Feedforward Voltage Estimation Improved with MRAS Multiparameter Estimation. IEEE/ASME Trans. Mechatron. 2018, 23, 1326-1337. [CrossRef]

7. Liu, X.; Chen, H.; Zhao, J.; Belahcen, A. Research on the Performances and Parameters of Interior PMSM Used for Electric Vehicles. IEEE Trans. Ind. Electron. 2016, 63, 3533-3545. [CrossRef]

8. Casadei, D.; Profumo, F.; Serra, G.; Tani, A. FOC and DTC: Two viable schemes for induction motors torque control. IEEE Trans. Power Electron. 2002, 17, 779-787. [CrossRef]

9. Takahashi, I.; Noguchi, T. A new quick-response and high-efficiency control strategy of an induction motor. IEEE Trans. Ind. Appl. 1986, IA-22, 820-827. [CrossRef]

10. Bird, I.G.; Zelaya De La Parra, H. Fuzzy logic torque ripple reduction for DTC based AC drives. Electron. Lett. 1997, 33, 1501-1502. [CrossRef]

11. Zhong, L.; Rahman, M.F.; Hu, W.Y.; Lim, K.W. Analysis of direct torque control in permanent magnet synchronous motor drives. IEEE Trans. Power Electron. 1997, 12, 528-536. [CrossRef]

12. Kang, J.; Sul, S. New direct torque control of induction motor for minimum torque ripple and constant switching frequency. IEEE Trans. Ind. Appl. 1999, 35, 1076-1082. [CrossRef]

13. Zhong, L.; Rahman, M.F.; Hu, W.Y.; Lim, K.W.; Rahman, M.A. A direct torque controller for permanent magnet synchronous motor drives. IEEE Trans. Energy Convers. 1999, 14, 637-642. [CrossRef]

14. Romeral, L.; Aria, A.; Aldabas, E.; Jayne, M.G. Novel direct torque control (DTC) scheme with fuzzy adaptive torque-ripple reduction. IEEE Trans. Ind. Electron. 2003, 50, 487-492. [CrossRef]

15. Kouro, S.; Cortes, P.; Vargas, R.; Ammann, U.; Rodriguez, J. Model predictive control—A simple and powerful method to control power converters. IEEE Trans. Ind. Electron. 2009, 56, 1826-1838. [CrossRef]

16. Cortes, P.; Kazmierkowski, M.P.; Kennel, R.M.; Quevedo, D.; Rodriguez, J. Predictive control in power electronics and drives. IEEE Trans. Ind. Electron. 2008, 55, 4312-4324. [CrossRef]

17. Rodriguez, J.; Kazmierkowski, M.P.; Espinoza, J.R.; Zanchetta, P.; Abu-Rub, H.; Young, H.A.; Rojas, C.A. State of the art of finite control set model predictive control in power electronics. IEEE Trans. Ind. Informat. 2013, 9, 1003-1016. [CrossRef]

18. Geyer, T. Model predictive direct torque control: Derivation and analysis of the state-feedback control law. IEEE Trans. Ind. Appl. 2013, 49, 2146-2157. [CrossRef]

19. Zhang, Y.; Yang, H. Model predictive torque control of induction motor drives with optimal duty cycle control. IEEE Trans. Power Electron. 2014, 29, 6593-6603. [CrossRef] 
20. Zhang, Y.; Yang, H. Generalized two-vector-based model-predictive torque control of induction motor drives. IEEE Trans. Power Electron. 2015, 30, 3818-3829. [CrossRef]

21. Vafaie, M.H.; Dehkordi, B.M.; Moallem, P.; Kiyoumarsi, A. A new predictive direct torque control method for improving both steady-state and transient-state operations of the PMSM. IEEE Trans. Power Electron. 2016, 31, 3738-3753. [CrossRef]

22. Nikzad, M.R.; Asaei, B.; Ahmadi, S.O. Discrete Duty-Cycle-Control Method for Direct Torque Control of Induction Motor Drives with Model Predictive Solution. IEEE Trans. Power Electron. 2018, 33, 2317-2329. [CrossRef]

23. Ban, F.; Lian, G.; Zhang, J.; Chen, B.; Gu, G. Study on a Novel Predictive Torque Control Strategy Based on the Finite Control Set for PMSM. IEEE Trans. Appl. Supercond. 2019, 29, 1-6. [CrossRef]

24. Wang, T.; Liu, C.; Lei, G.; Guo, Y.; Zhu, J. Model predictive direct torque control of permanent magnet synchronous motors with extended set of voltage space vectors. IET Electr. Power Appl. 2017, 11, 1376-1382. [CrossRef]

25. Navardi, M.J.; Milimonfared, J.; Talebi, H.A. Torque and Flux Ripples Minimization of Permanent Magnet Synchronous Motor by a Predictive-Based Hybrid Direct Torque Control. IEEE J. Emerg. Sel. Top. Power Electron. 2018, 6, 1662-1670. [CrossRef]

26. Preindl, M.; Bolognani, S. Model Predictive Direct Torque Control with Finite Control Set for PMSM Drive Systems, Part 1: Maximum Torque Per Ampere Operation. IEEE Trans. Ind. Inform. 2013, 9, 1912-1921. [CrossRef]

27. Vargas, R.; Cortes, P.; Ammann, U.; Rodriguez, J.; Pontt, J. Predictive control of a three-phase neutral-point-clamped inverter. IEEE Trans. Ind. Electron. 2007, 54, 2697-2705. [CrossRef]

28. Vargas, R.; Ammann, U.; Rodriguez, J.; Pontt, J. Predictive strategy to control common-mode voltage in loads fed by matrix converters. IEEE Trans. Ind. Electron. 2008, 55, 4372-4380. [CrossRef]

29. Cortes, P.; Rodriguez, J.; Silva, C.; Flores, A. Delay compensation in model predictive current control of a three-phase inverter. IEEE Trans. Ind. Electron. 2012, 59, 1323-1325. [CrossRef]

30. Habibullah, M.; Lu, D.D.; Xiao, D.; Rahman, M.F. A Simplified Finite-State Predictive Direct Torque Control for Induction Motor Drive. IEEE Trans. Ind. Electron. 2016, 63, 3964-3975. [CrossRef]

31. Xu, Y.; Li, Y.; Zhou, Q.; Li, Z. A Double Vectors Selection Direct Torque Control Strategy of Permanent Magnet Synchronous Motor. Proc. CSEE 2018, 38, 5211-5218.

32. Dinavahi, V.; Iravani, M.; Bonert, R. Real-time digital simulation of power electronic apparatus interfaced with digital controllers. IEEE Trans. Power Del. 2001, 16, 775-781. [CrossRef]

33. Demetriades, G.D.; de la Parra, H.Z.; Andersson, E.; Olsson, H. A real-time thermal model of a permanent-magnet synchronous motor. IEEE Trans. Power Electron. 2010, 25, 463-474. [CrossRef]

34. Allgre, A.-L.; Bouscayrol, A.; Verhille, J.-N.; Delarue, P.; Chattot, E.; El-Fassi, S. Reduced-scale-power hardware-in-the-loop simulation of an innovative subway. IEEE Trans. Ind. Electron. 2010, 57, 1175-1186. [CrossRef]

35. Musallam, M.; Johnson, C.M. Real-time compact thermal models for health management of power electronics. IEEE Trans. Power Electron. 2010, 25, 1416-1425. [CrossRef]

36. Vekić, M.S.; Grabić, S.U.; Majstorović, D.P.; Čelanović, I.L.; Čelanović, N.L.; Katić, V.A. Ultralow Latency HIL Platform for Rapid Development of Complex Power Electronics Systems. IEEE Trans. Power Electron. 2012, 27, 4436-4444. [CrossRef]

37. Abdelrahman, A.S.; Algarny, K.S.; Youssef, M.Z. A Novel Platform for Powertrain Modeling of Electric Cars with Experimental Validation Using Real-Time Hardware in the Loop (HIL): A Case Study of GM Second Generation Chevrolet Volt. IEEE Trans. Power Electron. 2018, 33, 9762-9771. [CrossRef]

(C) 2019 by the authors. Licensee MDPI, Basel, Switzerland. This article is an open access article distributed under the terms and conditions of the Creative Commons Attribution (CC BY) license (http:/ / creativecommons.org/licenses/by/4.0/). 